\title{
Foreword to the Special Issue on Subjective Approaches to Thermal Perception
}

\author{
Sanda Lenzholzer ${ }^{1}$ (D) - Marialena Nikolopoulou ${ }^{2}$ (D)
}

Published online: 17 January 2020

(C) ISB 2020

The last few years have seen an increasing amount of research in a relatively new area of biometeorology, the intersection of outdoor thermal comfort studies with environmental psychology. Focusing on people not as mere recipients of the complex radiation exchanges outdoors and processes aiming to reach equilibrium with the internal thermoregulatory processes, but actively engaging with the perception of these thermal processes, has revealed a new perspective of understanding outdoor thermal experience, enriching the scientific discourse internationally.

This new focus on the more subjective human parameter has provided a complimentary paradigm, highlighting the importance of personal, behavioural and psychological factors in outdoor thermal perception (Nikolopoulou et al. 2001; Nikolopoulou 2011). These new approaches have been increasingly adopted across the world at different geographic and climatic contexts (e.g. Stathopoulos et al. 2004; Nikolopoulou and Lykoudis 2006; Knez and Thorsson 2006; Thorsson et al. 2007 Knez and Thorsson 2008; Knez et al. 2009; Lin 2009, Lenzholzer 2010; Lenzholzer and Koh 2010; Lenzholzer and van der Wulp 2010, Aljawabra and Nikolopoulou 2010; Klemm et al. 2015b; Klemm et al. 2015a; Cortesão et al. 2016; Shih et al. 2017; Shooshtarian and Rajagopalan 2017) and a lively interdisciplinary field of research has emerged.

This special issue has been developed to reflect on these developments, specifically the subjective side of outdoor thermal perception and comfort, addressing a range of suitable methods for such investigations.

Sanda Lenzholzer

sanda.lenzholzer@wur.nl

Marialena Nikolopoulou

M.Nikolopoulou@kent.ac.uk

1 Landscape Architecture and Spatial Planning Group, Wageningen University, P.O. box 47, 6700 AA Wageningen, The Netherlands

2 Kent School of Architecture and Planning, University of Kent, Canterbury CT2 7NR, UK

\section{Why now?}

The reasons to shed light on these aspects are manifold. First of all, in recent years, the research paradigms to study human perception have increasingly included constructivist approaches that reflect a subjective perspective of human perceptions (Creswell 2014). A main approach within this paradigm is phenomenology that sees human multisensory sensations and the subjective interpretation of these as central themes of 'perception' (Heschong 1979; Husserl 1960; Merleau-Ponty 1992). In line with these developments, embracing such phenomenological approaches seems necessary to supplement the predominantly positivist discourse in thermal perception studies.

Secondly, environmental psychology has significantly advanced in the past years and provided new ways of collecting data on people's experience of their environment, including the thermal environment (Knez 2005; Lenzholzer and van der Wulp 2010). These recent developments had significant repercussions in the disciplines that shape human environments and thus the thermal environment (e.g. architecture, urban design, landscape architecture), as they aim at creating environments that respond to these perceptions. Phenomenological and psychological approaches have become relevant approaches to support design decisions in these disciplines (Pallasmaa 2005). In line with these developments, phenomenological and psychological perspectives have gained importance and been taken into account in recent research on thermal perception.

Finally, the rapid development of social media and internet of things provide new approaches to collecting information from different populations which would not have been possible 20 years ago. Such progress in disparate fields has suggested it is timely to provide an overview of these recent developments through this special issue and provide an outlook into promising future concepts and methods. 


\section{Contents and highlights}

The special issue includes a range of methodological approaches in the field of outdoor thermal comfort, as well as geographical spread and climatic zones (Fig. 1).

Out of the 13 papers, seven focus in cities outside Europe: from the winter city of Harbin (Leng et al.), to the continental Northeast USA (Giuffrida et al), and the more temperate climate city of Adelaide (Sharifi and Boland), to the tropical cities of Sao Paolo (Faustini et al.), New Delhi (Manavvi and Rajasekar), Dhaka (Sharmin and Steemers) and the drier conditions of Phoenix and Marrakesh (Aljawabra and Nikolopoulou). The European context is analysed in five papers focusing on the cities of Amsterdam (Klok et al.), Toulouse (Lemonsu et al.), Porto (Cortesão et al.), Rome and London (Vasilikou and Nikolopoulou), Athens, Thessalonica, Milan, Fribourg, Kassel, Cambridge and Sheffield (Pantavou et al.). This international coverage confirms the global reach and importance of the remit of outdoor thermal comfort (Table 1).

The work submitted to this special issue reflects a methodological variation, focusing on different aspects of thermal perception and comfort. The work includes mixed methods, some more established than others for the specific cognate area. Phenomenological and ethnographic approaches complement more traditional methods collecting data and comparing subjective with objective methods to draw relevant conclusions. Innovative social media platforms such as twitter are also included (Giuffrida et al.), highlighting potential next steps in capturing large-scale subjective data from multiple areas, surpassing the difficulties of traditional comfort surveys, as well as theoretical position papers aiming to construct an extended model of thermal perception (Lenzholzer and de Vries).

The different contributions ultimately aim to understand thermal perception, the driving forces behind it and how these can be employed in design and planning of our cities, as well as different prediction and warning systems for the public. The notion of adaptation and environmental diversity becomes integral for health and well-being under the unprecedented global warming that our cities face.

\section{Methodological approaches}

Integral to all the approaches presented in the different studies is the need to triangulate evidence from the different surveys studying human perspectives (whether through interviews, or observations) with meteorological measurements available at different scales, from the microclimate participants' experience to weather stations.

Portable meteorological stations have been employed, usually accompanying structured surveys with members of the population in transverse surveys. In studying the subjective perspective, different approaches have been followed: from passive activity observations to estimated thermal adaptation in Adelaide (Sharifi and Boland) to the use of photographic comparisons in Porto (Cortesão et al.), and photographic records in Sao Paolo to measure exposure times (Faustini et al.).

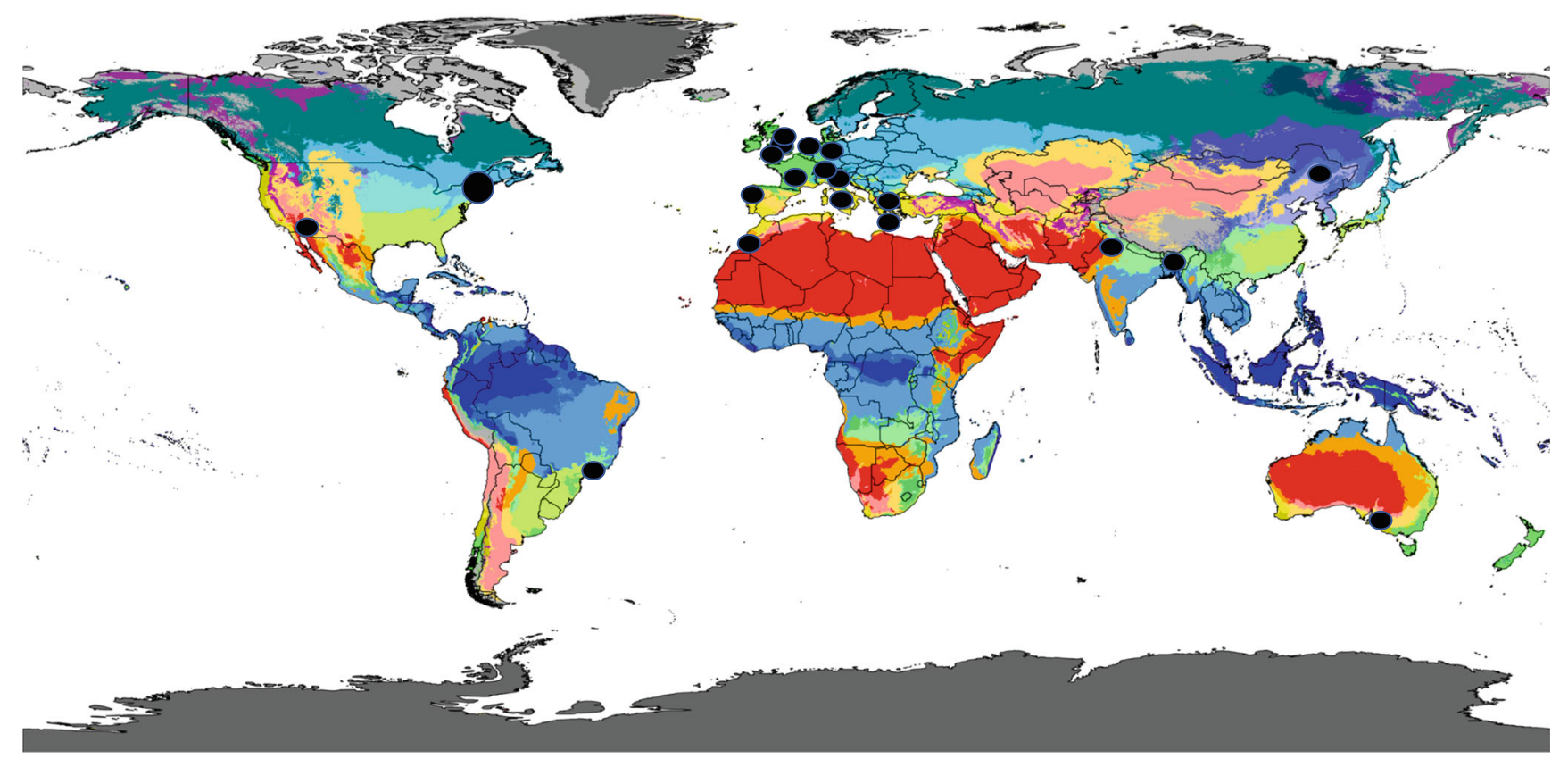

Fig. 1 Köppen climate zone map depicting the geographic and climatic distribution of the cities and regions investigated in the current special issue (adapted from: commons.wikimedia.org) 
Table 1 Authors and titles of articles in the current special issue

\begin{tabular}{|c|c|c|}
\hline Authors & Title & doi \\
\hline S. Lenzholzer and M. Nikolopoulou & $\begin{array}{l}\text { Foreword to the Special Issue on Subjective } \\
\text { Approaches to Thermal Perception }\end{array}$ & $10.1007 / \mathrm{s} 00484-019-01857-0$ \\
\hline J. Cortesão, F.B. Alves and K. Raaphorst & $\begin{array}{l}\text { Photographic comparison: a method } \\
\text { for qualitative outdoor thermal } \\
\text { perception surveys }\end{array}$ & $10.1007 / \mathrm{s} 00484-018-1575-6$ \\
\hline T. Sharmin and K. Steemers & $\begin{array}{l}\text { Effects of microclimate and human parameters on } \\
\text { outdoor thermal sensation in the high-density } \\
\text { tropical context of Dhaka }\end{array}$ & $10.1007 / \mathrm{s} 00484-018-1607-2$ \\
\hline $\begin{array}{l}\text { K. Pantavou, S. Lykoudis, M. Nikolopoulou and I.X. } \\
\text { Tsiros }\end{array}$ & $\begin{array}{l}\text { Thermal sensation and climate: a comparison } \\
\text { of UTCI and PET thresholds in } \\
\text { different climates }\end{array}$ & $10.1007 / \mathrm{s} 00484-019-01820-\mathrm{z}$ \\
\hline L. Giuffrida, H. Lokys and O. Klemm & $\begin{array}{l}\text { Assessing the effect of weather on human outdoor } \\
\text { perception using Twitter }\end{array}$ & $10.1007 / \mathrm{s} 00484-018-1574-7$ \\
\hline H. Leng, S. Liang and Q. Yuan & $\begin{array}{l}\text { Outdoor thermal comfort and adaptive behaviors } \\
\text { in the residential public open spaces of winter } \\
\text { cities during the marginal season }\end{array}$ & $10.1007 / \mathrm{s} 00484-019-01709-\mathrm{x}$ \\
\hline E. Sharifi and J. Boland & $\begin{array}{l}\text { Passive activity observation (PAO) method to } \\
\text { estimate outdoor thermal adaptation in public } \\
\text { space: case studies in Australian cities }\end{array}$ & $10.1007 / \mathrm{s} 00484-018-1570-\mathrm{y}$ \\
\hline $\begin{array}{l}\text { F.B. Faustini, J.R. Gomes de Faria and M.S.G. de Castro } \\
\text { Fontes }\end{array}$ & $\begin{array}{l}\text { The influence of thermal comfort conditions } \\
\text { on user's exposure time in open spaces }\end{array}$ & $10.1007 / \mathrm{s} 00484-019-01749-3$ \\
\hline S. Manavvi and E. Rajasekar & $\begin{array}{l}\text { Semantics of outdoor thermal comfort in religious } \\
\text { squares of composite climate: New Delhi, India }\end{array}$ & 10.1007/s00484-019-01708-y \\
\hline L. Klok, N. Rood, J. Kluck and L. Kleerekoper & $\begin{array}{l}\text { Assessment of thermally comfortable urban } \\
\text { spaces in Amsterdam during hot summer days }\end{array}$ & $10.1007 / \mathrm{s} 00484-019-01818-7$ \\
\hline $\begin{array}{l}\text { A. Lemonsu, A. Amossé, D. Chouillou, N. Gaudio, S. } \\
\text { Haouès- Jouve, J. Hidalgo, J. Le Bras, D. Legain, S. } \\
\text { Marchandise and B. Tudoux }\end{array}$ & $\begin{array}{l}\text { Comparison of microclimate measurements and } \\
\text { perceptions as part of a global evaluation of } \\
\text { environmental quality at neighbourhood scale }\end{array}$ & $10.1007 / \mathrm{s} 00484-019-01686-1$ \\
\hline C. Vasilikou and M. Nikolopoulou & $\begin{array}{l}\text { Outdoor thermal comfort for pedestrians in } \\
\text { movement: thermal walks in complex urban } \\
\text { morphology }\end{array}$ & $10.1007 / \mathrm{s} 00484-019-01782-2$ \\
\hline F. Aljawabra and M. Nikolopoulou & $\begin{array}{l}\text { Thermal comfort in urban spaces: a cross-cultural } \\
\text { study in the hot arid climate }\end{array}$ & $10.1007 / \mathrm{s} 00484-019-01819-6$ \\
\hline S. Lenzholzer and S. de Vries & $\begin{array}{l}\text { Exploring outdoor thermal perception }-\mathrm{a} \\
\text { revised model }\end{array}$ & $10.1007 / \mathrm{s} 00484-019-01777-\mathrm{z}$ \\
\hline
\end{tabular}

To overcome the need for collecting wider samples to represent a population, two studies used longitudinal methods with structured walks with small groups. Lemonsu et al. consider thermal perception as one of the components of environmental perception in Toulouse, while Vasilikou and Nikolopoulou organised a series of thermal walks in London and Rome in different seasons, to evaluate the variation of thermal perception in the urban fabric, highlighting the role of walking in thermal diversity.

At the regional scale, Giuffrida et al. demonstrate how twitter can provide meaningful information on linking tweets containing weather-associated words with thermal perception, while linking with real-time meteorological data. This study successfully paves the way for further employment of social media platforms and Internet of Things in the wider thermal comfort debate.

Regarding evaluation methods, in many of the studies, there is an attempt to link subjective indicators of thermal sensations as collected from the surveys with different indicators from literature, predominantly developed for outdoor use. From the range of theoretical indicators presented in the special issue, the most widely used have been the physiological equivalent temperature (PET) and universal thermal comfort index (UTCI), employed by Sharifi and Boland, Manavvi and Rajasekar, as well as Pantavou et al., while Klok et al. and Leng et al. use PET. All these studies are aiming to quantify different aspects of adaptation, whether through linking with thermal sensation or thresholds as a function of different climatic parameters. Another useful approach highlights the use of existing datasets and the need for developing open-access data. With the increasing occurrence of outdoor comfort surveys across the world, this can become an important resource which can allow further analysis in the future. One such study is the paper by Pantavou el al., who use meta-analysis of the largest publically available dataset on outdoor thermal comfort to-date, that of project RUROS (CRES 2004), to quantify the contribution of climate to the long-term thermal adaptation. 
Many authors discuss the effect of design-related parameters on thermal comfort; however, Klok et al. succeed in also quantifying such influence, linking the cooling effect of green, shade and water with thermal comfort based on measurements as well as surveys. Shading appears to be the most influential parameter during hot weather, and such information is critical for urban planners and other professionals who may be tasked with reducing urban heat.

\section{Activities}

Outdoor spaces can support a range of activities and can play an important role for health and well-being both directly, allowing outdoor activities to take place, including walking and exercising, as well as indirectly supporting informal activities, socialising, to providing suitable conditions for cooling when the indoor environment becomes unhospitable. Different authors discuss activity across a wide spectrum from essential to optional, static to dynamic.

In the winter city of Harbin, Leng et al., focusing on residential open spaces, highlight the low thermal threshold value of $10.2^{\circ} \mathrm{C}$ for outdoor activities and how design can be employed to increase the marginal season.

Similarly, Sharifi and Boland, differentiating between social and necessary activities, highlighted the wide range of thermal conditions between the two types. Once again, thermal adaptation varied widely between different sites, depending on supportive land use, as well as spatial and landscape features.

These are also the results of Faustini et al., who investigate time of exposure in two different areas in the zoo of Baaru, Sao Paolo. Although use of different areas was similar in relation to the number of people visiting the different areas, people spent longer time in the spaces with more favourable microclimatic conditions, i.e. better shading.

One typology of open spaces that had not been investigated before, but where outdoor comfort conditions have a considerable influence, is religious spaces. These provide the framework for the analysis of Manavvi and Rajasekar, in two religious squares is New Delhi. Adaptation elements such as from solar exposure and landscape, as well as implicit physiological factor such as intent of visit and thermal history, have a significant effect on thermal perception. Particularly for those visiting the squares for religious purposes, neutral PET was $2.7^{\circ} \mathrm{C}$ higher than those visiting for non-worship purposes, once again highlighting the importance of psychological adaptation.

\section{Social construct?}

Socio-economic and cultural backgrounds are rarely investigated in outdoor comfort surveys. It is generally acknowledged that outdoor space is predominately accessible to all.
Although there is specific mention to spaces drawing people from different economic backgrounds and social hierarchies in the special issue, such as the religious squares, this is explicitly discussed by Aljawabra and Nikolopoulou. Focusing on a similar hot arid climate of Marrakech in Morocco and Phoenix in Arizona, they highlight the effect such factors can have on thermal comfort. Due to the prevalence of air conditioning in Phoenix, people were more sensitive to changes in air temperature and solar radiation, demonstrating a narrower comfort zone. Interestingly, in both cities, people from lower socio-economic background were found to be comfortable at a wider range of temperatures. Given the financial and environmental expense of using air conditioning, comfortable outdoor spaces can thus provide suitable alternatives supporting outdoor activities for different population groups.

\section{What for the future?}

The special issue concludes with a position paper by Lenzholzer and de Vries. They assess the recent literature on outdoor thermal perception, aiming to develop an extended model of thermal perception that explicitly includes the subjective approaches, identifying knowledge gaps and suggesting new methods to study outdoor thermal perception. From refinement of the development or thermal indices to multisensory perception or technological developments, and immersive experiences, whether physical or digital, we are still in the infancy of fully articulating and quantifying the psychological aspect of thermal perception. Although the model still remains speculative, the evidence provided throughout this special issue has highlighted a number of important issues.

Where personal data is not available, predictive models can be useful to inform comfort conditions and justify the efforts using publicly available data sources. The recurrent theme across the submissions highlights the important role of adaptation in supporting human activities. In this framework, design can be viewed as integral to increase environmental diversity and enhance adaptive capacity. This requires collaboration between different disciplines and understanding of semantics of different fields: from land use to urban morphology, to natural or other design interventions, all highlighting the importance of the network of open spaces. This aligns with the findings from a recent special issue from the built environment, which demonstrated that the fabric-first approach focusing on buildings as isolated entities need to be revisited (Emmanuel and Steemers 2018).

Undoubtedly, we foresee a need for further research in the field. Focusing on the most densely populated regions, such as Southeast Asia, Africa and South America, can provide evidence for the critical role of open spaces, as well as health and well-being. In a changing climate, thermal perception is paramount to the development of comfortable open spaces, which not only increase resilience but also enable social justice 
ensuring access to comfortable environments to the wider population.

Acknowledgements The editorial work on this special issue was partly funded by the Research fellow fund of the Wageningen Institute for Environment and Climate Research (WIMEK).

\section{References}

Aljawabra F, Nikolopoulou M (2010) Influence of hot arid climate on the use of outdoor urban spaces and thermal comfort: do cultural and social backgrounds matter? Intell Build Int 2(3):198-217. https:// doi.org/10.3763/inbi.2010.0046

Cortesão J, Alves FB, Corvacho H, Rocha C (2016) Retrofitting public spaces for thermal comfort and sustainability. Indoor Built Environ 25(7):1085-1095. https://doi.org/10.1177/1420326x16659326

CRES, Centre for Renewable Energy Sources (2004) RUROS project \& database, http://alpha.cres.gr/ruros

Creswell JW (2014) Research design : qualitative, quantitative, and mixed methods approaches. SAGE Publications, Thousand Oaks

Emmanuel R, Steemers K (2018) Connecting the realms of urban form, density and microclimate. Build Res Inf 46(8):804-808. https://doi. org/10.1080/09613218.2018.1507078

Heschong L (1979) Thermal delight in architecture. Mass, MIT Press, Cambridge

Husserl E (1960) Cartesian meditations- an introduction to phenomenology (trans: Cairns D). Martinus Nijhoff, Den Haag

Klemm W, Heusinkveld BG, Lenzholzer S, Jacobs MH, Van Hove B (2015a) Psychological and physical impact of urban green spaces on outdoor thermal comfort during summertime in The Netherlands. Build Environ 83:120-128. https://doi.org/10.1016/j.buildenv.2014. 05.013

Klemm W, Heusinkveld BG, Lenzholzer S, van Hove B (2015b) Street greenery and its physical and psychological impact on thermal comfort. Landsc Urban Plan 138:87-98. https://doi.org/10.1016/j. landurbplan.2015.02.009

Knez I (2005) Attachment and identity as related to a place and its perceived climate. J Environ Psychol 25(2):207-218. https://doi.org/ 10.1016/j.jenvp.2005.03.003

Knez I, Thorsson S (2006) Influences of culture and environmental attitude on thermal, emotional and perceptual evaluations of a public square. Int J Biometeorol 50(5):258-268. https://doi.org/10.1007/ s00484-006-0024-0

Knez I, Thorsson S (2008) Thermal, emotional and perceptual evaluations of a park: cross-cultural and environmental attitude comparisons. Build Environ 43(9):1483-1490. https://doi.org/10.1016/j. buildenv.2007.08.002
Knez I, Thorsson S, Eliasson I, Lindberg F (2009) Psychological mechanisms in outdoor place and weather assessment: towards a conceptual model. Int J Biometeorol 53(1):101-111. https://doi.org/10. 1007/s00484-008-0194-z

Lenzholzer S (2010) Engrained experience-a comparison of microclimate perception schemata and microclimate measurements in Dutch urban squares. Int J Biometeorol 54(2):141-151 https://link.springer. com/article/10.1007\%2Fs00484-009-0262-z

Lenzholzer S, Koh J (2010) Immersed in microclimatic space: microclimate experience and perception of spatial configurations in Dutch squares. Landsc Urban Plan 95:1-15. https://doi.org/10.1016/j. landurbplan.2009.10.013

Lenzholzer S, van der Wulp NY (2010) Thermal experience and perception of the built environment in Dutch urban squares. J Urban Des 15(3):375-401

Lin T-P (2009) Thermal perception, adaptation and attendance in a public square in hot and humid regions. Build Environ 44(10):2017-2026. https://doi.org/10.1016/j.buildenv.2009.02.004

Merleau-Ponty M (1992) The phenomenology of perception. Routledge, London

Nikolopoulou M (2011) Outdoor thermal comfort. Front Biosci 3:15521568. https://doi.org/10.2741/245

Nikolopoulou M, Lykoudis S (2006) Thermal comfort in outdoor urban spaces: analysis across different European countries. Build Environ 41(11):1455-1470. https://doi.org/10.1016/j.buildenv.2005.05.031

Nikolopoulou M, Baker N, Steemers K (2001) Thermal comfort in outdoor urban spaces: understanding the human parameter. Sol Energy 70(3):227-235. https://doi.org/10.1016/S0038-092X(00)00093-1

Pallasmaa J (2005) The eyes of the skin- architecture and the senses. Wiley and Sons, Chichester

Shih W-M, Lin T-P, Tan N-X, Liu M-H (2017) Long-term perceptions of outdoor thermal environments in an elementary school in a hothumid climate. Int J Biometeorol 61(9):1-10 https://link.springer. com/article/10.1007\%2Fs00484-017-1345-x

Shooshtarian S, Rajagopalan P (2017) Study of thermal satisfaction in an Australian educational precinct. Build Environ 123:119-132. https://doi.org/10.1016/j.buildenv.2017.07.002

Stathopoulos T, Wu H, Zacharias J (2004) Outdoor human comfort in an urban climate. Build Environ 39(3):297-305. https://doi.org/10. 1016/j.buildenv.2003.09.001

Thorsson S, Honjo T, Lindberg F, Eliasson I, Lim EM (2007) Thermal comfort and outdoor activity in Japanese urban public places. Environ Behav 39(5):660-684. https://doi.org/10.1177/ 0013916506294937

Publisher's note Springer Nature remains neutral with regard to jurisdictional claims in published maps and institutional affiliations. 